\title{
Strategies for improving physician documentation in the emergency department: a systematic review
}

\author{
Diane L. Lorenzetti ${ }^{1 *} \mathbb{D}$, Hude Quan ${ }^{1}$, Kelsey Lucyk', Ceara Cunningham', Deirdre Hennessy', Jason Jiang ${ }^{1}$ and \\ Cynthia A. Beck ${ }^{2}$
}

\begin{abstract}
Background: Physician chart documentation can facilitate patient care decisions, reduce treatment errors, and inform health system planning and resource allocation activities. Although accurate and complete patient chart data supports quality and continuity of patient care, physician documentation often varies in terms of timeliness, legibility, clarity and completeness. While many educational and other approaches have been implemented in hospital settings, the extent to which these interventions can improve the quality of documentation in emergency departments (EDs) is unknown.
\end{abstract}

Methods: We conducted a systematic review to assess the effectiveness of approaches to improve ED physician documentation. Peer reviewed electronic databases, grey literature sources, and reference lists of included studies were searched to March 2015. Studies were included if they reported on outcomes associated with interventions designed to enhance the quality of physician documentation.

Results: Nineteen studies were identified that report on the effectiveness of interventions to improve physician documentation in EDs. Interventions included audit/feedback, dictation, education, facilitation, reminders, templates, and multi-interventions. While ten studies found that audit/feedback, dictation, pharmacist facilitation, reminders, templates, and multi-pronged approaches did improve the quality of physician documentation across multiple outcome measures, the remaining nine studies reported mixed results.

Conclusions: Promising approaches to improving physician documentation in emergency department settings include audit/feedback, reminders, templates, and multi-pronged education interventions. Future research should focus on exploring the impact of implementing these interventions in EDs with and without emergency medical record systems (EMRs), and investigating the potential of emerging technologies, including EMR-based machinelearning, to promote improvements in the quality of ED documentation.

Keywords: Documentation, Emergency departments, Medical records, Physicians, Systematic reviews

\section{Introduction}

Chart accuracy is both a measure and a means of ensuring the quality of the care that patients receive [1]. Accurate patient chart information can facilitate and further communication between healthcare professionals involved in patient care, both in hospital and upon discharge into the community $[2,3]$. Conversely, poor documentation can

\footnotetext{
*Correspondence: dllorenz@ucalgary.ca

${ }^{1}$ Department of Community Health Sciences, Cumming School of Medicine, University of Calgary, 3330 Hospital Drive NW, Calgary, AB T2N4N1, Canada Full list of author information is available at the end of the article
}

affect continuity of patient care, particularly during care transitions, and may cause delays or errors in patient treatment [4-8]. In 2018, a retrospective review of 138 antibiotic orders found that incomplete documentation resulted in longer median time to order resolution compared with completed documentation (31 vs $10 \mathrm{~min}$, $p=0.02$ ) [8]. During another retrospective chart review of 2061 patients who had undergone carotid enarterectomy, researchers found that charts deemed to be poorly documented were less freqently associated with appropriate scheduling of carotid endarterectomy procedures than

(c) The Author(s). 2018 Open Access This article is distributed under the terms of the Creative Commons Attribution 4.0 International License (http://creativecommons.org/licenses/by/4.0/), which permits unrestricted use, distribution, and reproduction in any medium, provided you give appropriate credit to the original author(s) and the source, provide a link to the Creative Commons license, and indicate if changes were made. The Creative Commons Public Domain Dedication waiver (http://creativecommons.org/publicdomain/zero/1.0/) applies to the data made available in this article, unless otherwise stated. 
charts of high quality $(44.2 \%$ vs $52.9 \%, p<0.001)$ [7]. As patient chart data is routinely used for hospital reimbursement, health system planning, resource allocation, and research activities, data quality may also impact outcomes beyond those associated with direct patient care $[7,9,10]$.

Previous research suggests that considerable variation exists in the quality of physician documentation [7, 10, $11]$. In the previously cited study of patients who underwent carotid endarterectomy, researchers, using a 10 point rating scale, found that of 2061 charts reviewed, only $42.6 \%$ were rated as well documented, with the percentage of high quality charts ranging from 14.6 to $87.5 \%$ across the 17 hospitals that were sampled [7]. Patient volume, care complexity, the variety and number of healthcare professionals involved in individual patient care, and the use of unformatted paper charts can all contribute to poor chart documentation $[1,6,12]$.

Previous studies have demonstrated that a significant relationship exists between emergency department patient volume and errors or omissions in unformatted paper charts $[13,14]$. Emergency Departments (ED) are characterized by frequent staff changes, high activity levels, overcrowding, frequent interruptions, time pressures, uncertain patient arrival patterns, and a wide variety of case presentations [14-17]. In such environments, fraught with risks for poor chart documentation, there is a pressing need for methods to better promote the recording of accurate and complete patient care information.

In recent years, electronic medical record (EMR) systems have been introduced into many EDs to facilitate the documentation of patient care episodes [18-21]. Despite this recent surge in EMR uptake, the quality of data in EMR systems remains variable [22, 23]. While some researchers have reported that EMRs improve guideline adherence, and reduce medication errors [18, 24], others claim that EMRs are but "clumsy electronic versions of paper charts" which, while increasing "the amount of information recorded", do little to enhance the "readability" or overall quality of patient care information [25].

Research on the quality of EMR patient medical records tends to confirm that EMRs do not, by themselves, support enhanced physician documentation clarity, accuracy, completeness, or other measures of quality [26-31]. While some authors have found significant improvements in the accuracy, completeness, or richness (presence/completeness) of EMR documentation as compared with paper charts [26-29,31], others have reported mixed results. In 2009, Alkasab et al. found that while EMR records of ED patient encounters included more clinical questions and information on medical histories, handwritten notes contained more data and details on non-significant improvements in symptoms and test results [26]. Perry et al. (2014) further noted that ED physicians spent significantly more time entering data into EMR applications as compared with paper charts [30].

Since EMR information is "necessarily documentation dependent", strategies to enhance the quality of physician documentation can impact the accuracy, comprehensiveness, and usability of EMR records [32]. Further, as many emergency departments continue to rely on paper or hybrid charts, there is a broader need to identify and adopt effective approaches to documentation improvement that are not exclusively EMR-dependent. Such approaches may include: physician education, templates, dictation, and scanning of free-text paper notes into EMRs [33, 34].

The extent to which these and other interventions can improve documentation quality, particularly in the context of EDs, is, as yet, unclear. Thus, the objective of this study was to conduct a systematic review of the effectiveness of interventions to improve the quality of $\mathrm{ED}$ physician documentation in emergency settings.

\section{Methods}

We searched the Cochrane Library, DARE Database of Reviews of Effects, EMBASE, MEDLINE, PubMED, and Web of Science to March 2015 to identify relevant English and French language peer reviewed literature suitable for inclusion in this review. No date limits were applied. Sources of grey literature, including the University of York's Health Technology Database, Current Controlled Trials Register and the websites of government and professional organizations, were similarly searched. We also scanned the reference lists of included studies and review articles to identify additional studies of relevance to this review. This review was conducted in accordance with the Preferred Reporting Items for Systematic Reviews and Meta-Analyses (PRISMA) guidelines [35]. The protocol for this review has not been registered in PROSPERO or any other publicly accessible registry.

Search strategies combined search terms from two themes: 1) physicians (including but not limited to: clinician, physician, doctor, house officer, intern, resident, medical student) and 2) documentation (including but not limited to: administrative data, clinical coding, documentation, hospital record, medical chart). Terms were searched as both keywords and database subject headings as appropriate. No date limits were applied. An additional file is provided that outlines the search strategy used to identify relevant studies in the MEDLINE (OVID) database [see Additional file 1]. This MEDLINE (OVID) search was adapted to other electronic databases searched in this review. Copies of the complete search strategy are available, upon request, from the authors.

All abstracts were screened in duplicate, for inclusion in the full text review. Three authors independently screened the full texts of all selected abstracts. During both screening stages, disagreements were resolved 
through consensus. Studies were included if they reported on the results of any intervention to improve physician documentation in emergency settings. Studies were excluded if they 1) were descriptive studies or case reports, 2) reported only post-intervention results, 3) focused on populations other than physicians, residents or medical students, 4) centered on education to improve history taking, patient care for specific medical conditions, verbal communication skills, or the documentation of non-chart data, or 5) focused on documenting or evaluating student performance.

Four authors jointly extracted data from all included studies into a standardized form created in Excel. Outcomes of interest included: documentation accuracy, clarity (understandability), legibility, completeness, presence, and timeliness. Two authors independently assessed the quality of included studies, using the Downs and Black checklist of 27 quality criteria for randomized and non-randomized designs [36]. Due to the heterogeneity of study designs, and outcomes, it was not possible to pool the data from included studies.

\section{Results}

A total of 6188 unique abstracts were identified from electronic database and other searches. Four hundred and seventy-two of these were selected for full text review, 19 of which were deemed appropriate for inclusion in the final review (Fig. 1). One RCT, 6 quasi-experimental, and 12 pre-experimental (cross-sectional, or pre-post with no comparison) studies evaluated interventions to improve physician documentation in ED teaching and non-teaching hospitals and trauma centers in Australia ( $n$ $=3)$, Belgium $(n=1)$, Canada $(n=3)$ New Zealand $(n=1)$,

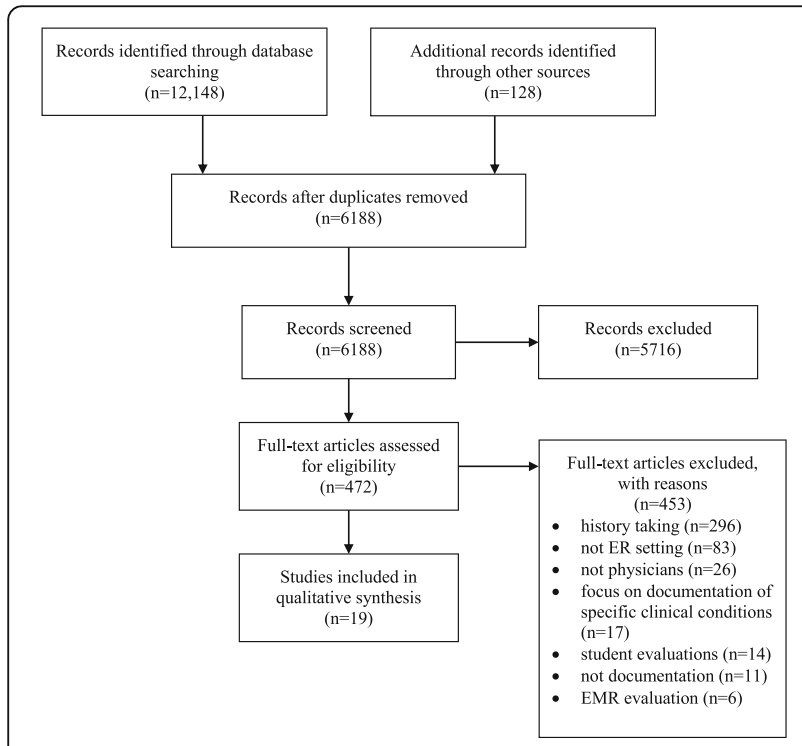

Fig. 1 PRISMA Flow Diagram
United Kingdom $(n=3)$ and the United States $(n=8)$ (Table 1).

The quality of included studies, per the Downs and Black scale, ranged from low $<15(n=3)$, to moderate 15-19 $(n=11)$, to high $>19(n=5)$ (Table 1$)$. Quality issues identified in most studies included the absence of descriptions of principle confounders $(n=10)$, and lack blinding of participants $(n=14)$ or those assessing the outcomes of interventions $(n=17)$.

Seven interventions were identified to improve physician documentation in ED settings. These included: audit/feedback $(n=2)$, dictation $(n=2)$, education $(n=1)$, facilitation $(n=1)$, reminders $(n=2)$, structured paper templates $(n=7)$, and multi-interventions $(n=4)$ that incorporated two or more approaches to improving documentation (Table 1).

\section{Audit/feedback}

Two studies (one time series, one pre-post without control) explored the impact of audit/feedback on improving ED documentation [37, 38]. In both studies, audit/feedback significantly improved the richness (presence and completeness) of physician documentation (Table 1).

\section{Dictation}

Two studies (one pre-post without control; one retrospective follow up with control) investigated dictation as a means of improving documentation quality [39, 40]. (Table 1) In a retrospective comparison of dictated and paper charts, Cole and Counselman (1995) reported significant improvements in the number of 28 critical items documented for patients presenting with chest pain [39]. Zick and Olsen (2001) compared voice recognition software (Dragon Naturally Speaking ${ }^{\circ}$ ) to traditional dictation. While completion time decreased with the use of voice recognition software (Dragon Naturally Speaking ${ }^{\circ}$ ) so too did the overall accuracy of physician documentation [40].

\section{Education}

One study (pre-post with control) evaluated the effectiveness of an education intervention, a $1 \mathrm{~h}$ lecture on medical liability, to improve residents' documentation of pediatric emergency charts [41]. Researchers found no difference in the richness (presence and completeness) of the charts documented post-lecture (Table 1).

\section{Facilitation}

One study (pre-post without control) evaluated the effects of a pharmacist intervention on the quality of physician documentation [42]. Researchers determined that pharmacists' involvement in recording medication histories for older patients taking 4 or more concurrent medications resulted in significantly fewer unintentional discrepancies in patients' usual drug regimens, and 


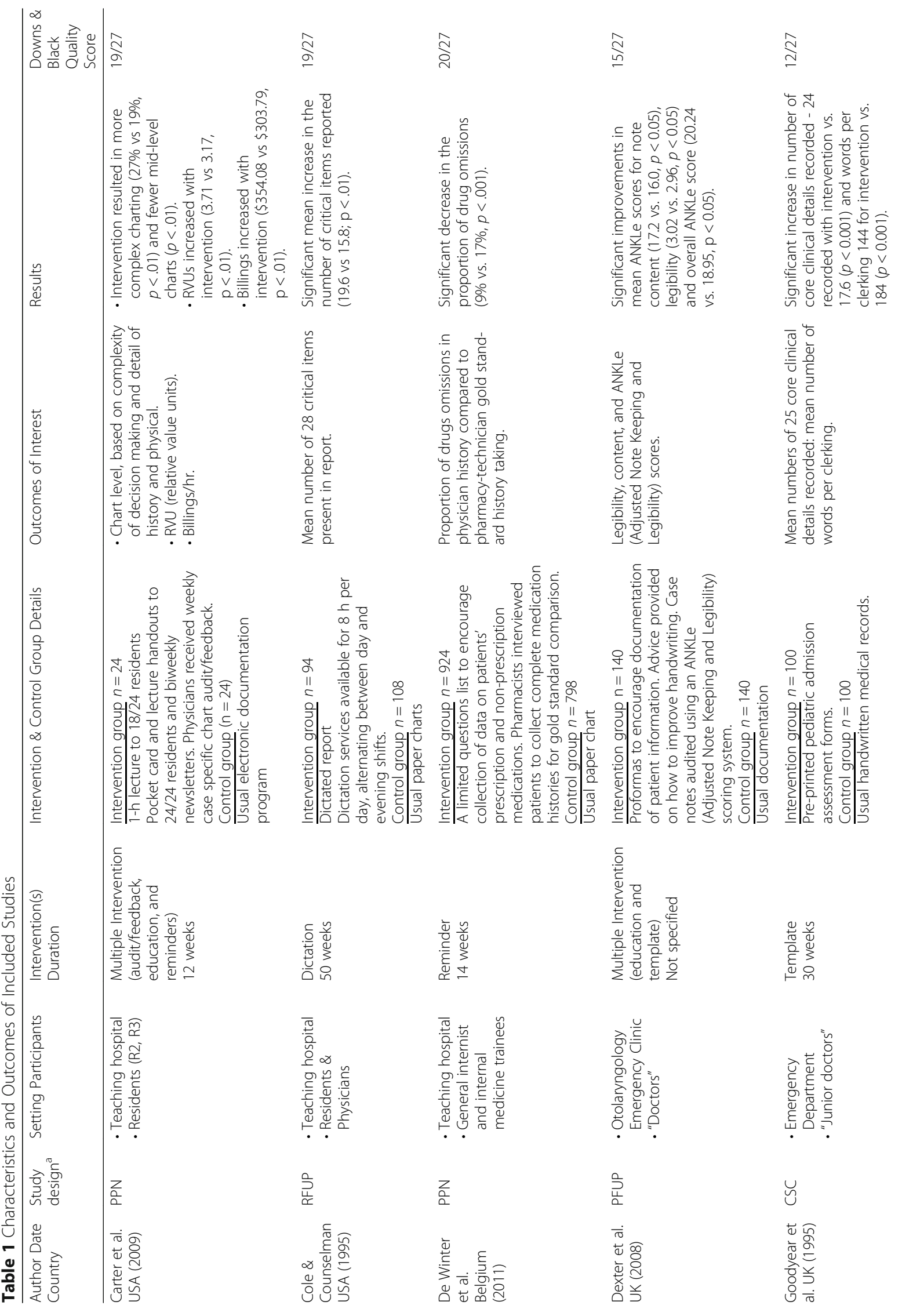




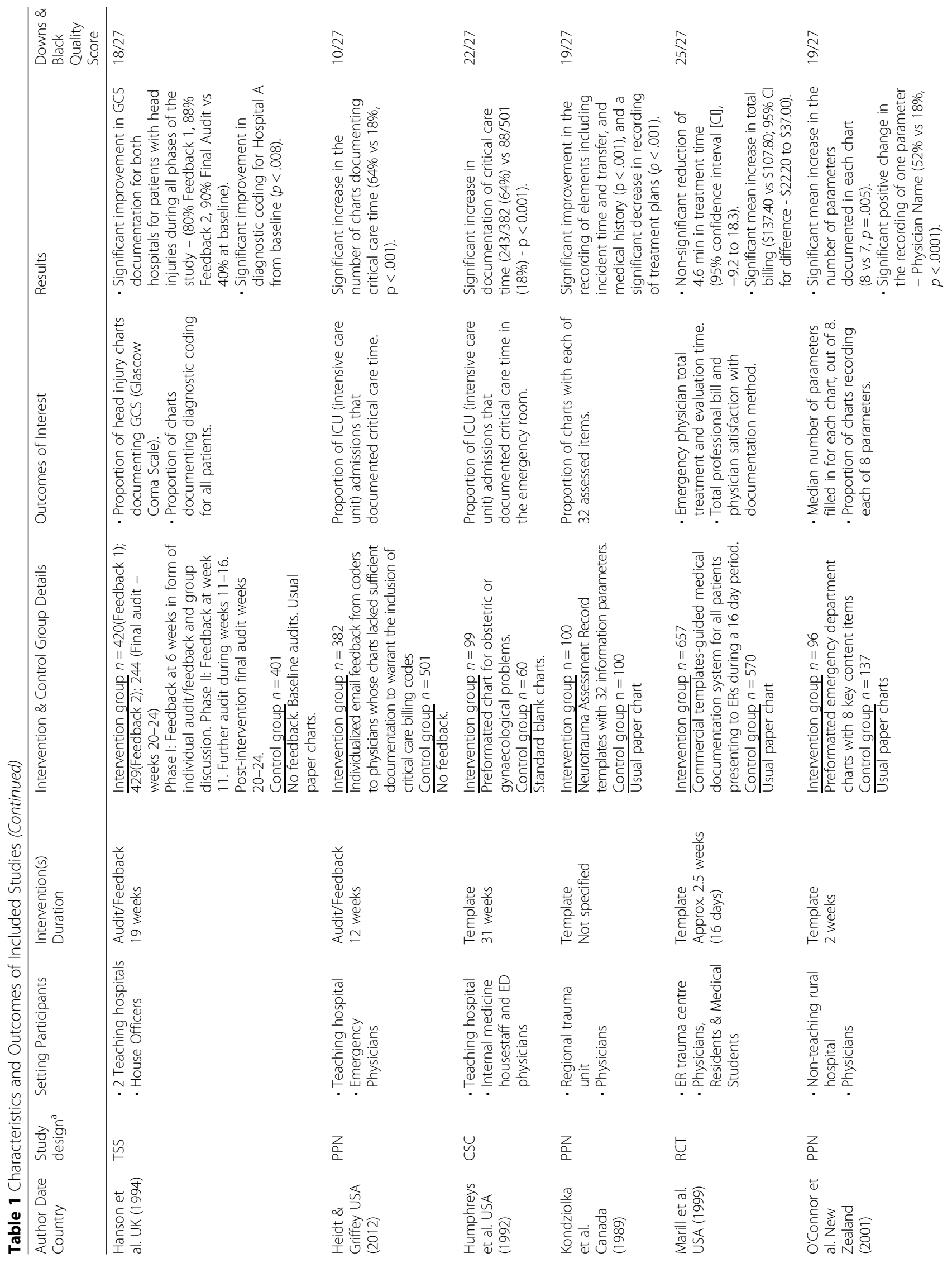




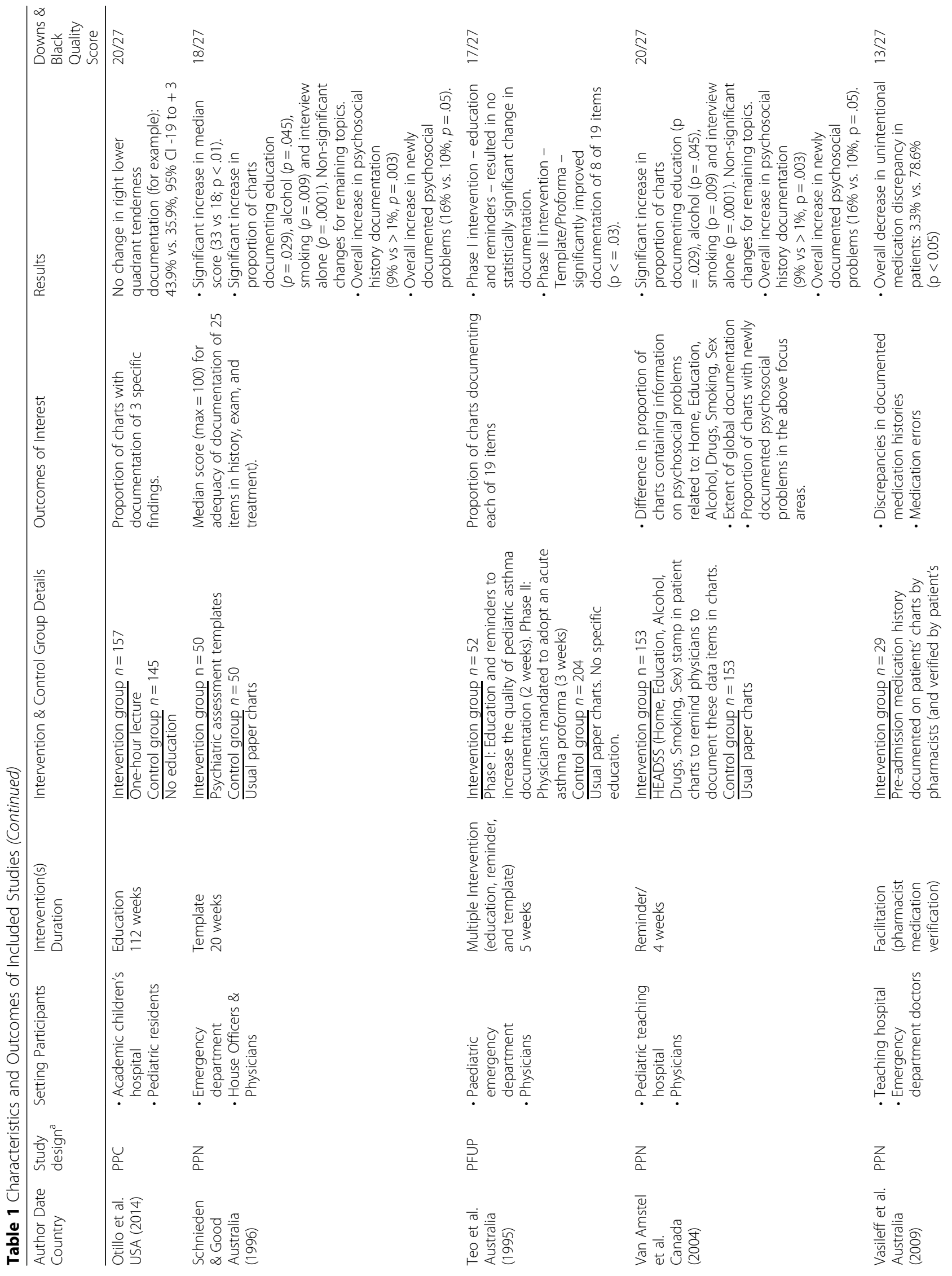




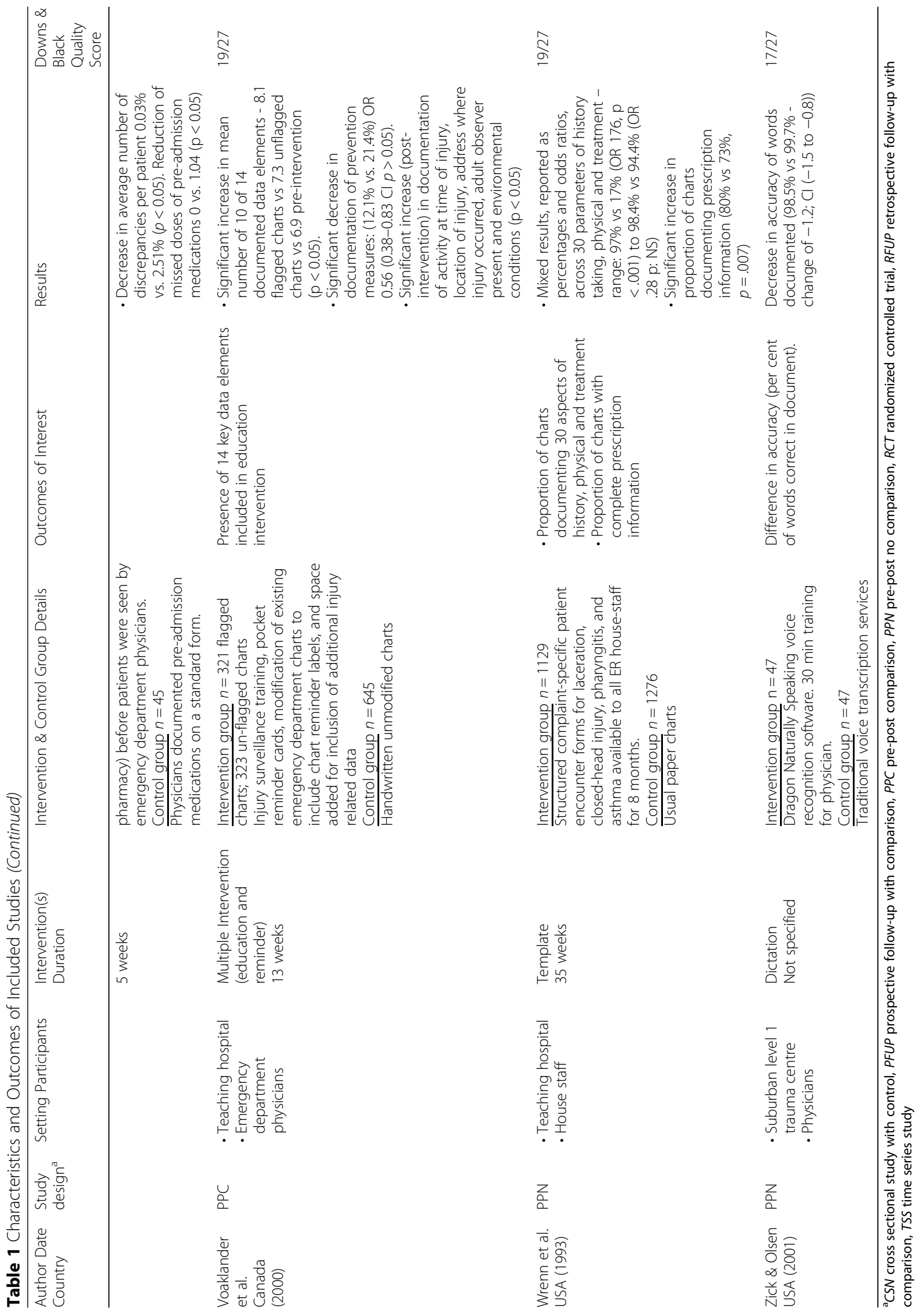


missed or incorrect medication doses prescribed to patients [42].

\section{Reminders}

In two studies (both pre-post without controls), researchers found that reminders, in the form of physician question lists or chart stamps, significantly improved the quality (presence of specified items) of physician documentation when compared with unformatted paper charts [43, 44]. While De Winter et al. (2011) reported a significant decrease in the number of drug history omissions, Van Armstel et al. (2004) noted a significant increase in overall documentation $[43,44]$.

\section{Templates/forms}

Seven studies (two cross-sectional control, four pre-post without control, one RCT) compared templates to unformatted paper charts [25, 45-50]. Three studies (two cross-sectional control, one pre-post without control) reported significant improvements in physician documentation $[45,46,49]$. The remaining four studies (three pre-post without control, one RCT) reported mixed results in intervention effectiveness [47, 48, 50, 51]. Kondziolka et al. (1989) noted improvements in recordings of incident time, patient transfer time, and medical history, but a decrease in the presence of patient treatment plans [47]. O'Connor et al. (2001) found that, while templates resulted in a significant mean increase in a number of "key content items," the only consistent improvement was in the recording of physicians' names [48]. Wrenn et al. (1993) reported that templates significantly improved physicians' recording of patient prescription information, yet achieved mixed results in the documentation of 30 items relevant to history taking, physicals, and the treatment of patients with asthma, lacerations, pharyngitis, or closed head injuries [50]. Finally, a randomized controlled trial by Marill et al. (1999) found that the use of templates did not significantly reduce patients' time to treatment [51].

\section{Multiple interventions}

Four studies (one pre-post without control, one pre-post control, two prospective follow up with comparison) assessed the impact of multi-interventions on the quality of physician documentation [52-55]. While all studies included an education component, they varied in the type and number of other interventions that were included. One study included audit/feedback and reminders; one templates; one reminders; and, one reminders and templates. Two of the four studies (one pre-post without comparison, one prospective follow up) reported positive results associated with the use of multi-interventions to improve documentation quality. Carter et al. (2009) found improvements in the completeness of physicians' chart documentation as a result of lectures, pocket reminders, and case-specific chart audit/feedback, and Dexter et al. (2008) reported that templates and education enhanced the richness (presence and completeness) and legibility of physicians' chart documentation in an otolaryngology emergency clinic [52, 53]. In contrast, Teo et al. (1995) found that, while the introduction of templates did improve physician documentation of required items for asthma diagnosis and reporting in a pediatric emergency department, education and reminders did not result in any significant increase in the presence and completeness of asthma documentation [54]. Finally, Voaklander et al. (2000) reported that pocket cards and chart labels significantly increased the number of items recorded for pediatric injuries, including activity at the time of injury, yet decreased documentation of injury prevention measures [55].

\section{Discussion}

Accurate and complete physician documentation is essential to ensuring that patients receive appropriate and timely care [56]. In environments where increasing numbers of healthcare organizations are digitizing patient health data and enabling data sharing among healthcare providers and health researchers, it is increasingly essential to ensure that these data are of the highest quality. Our study identified a number of promising strategies to improve the accuracy, completeness, and overall quality of physician documentation in EDs with and without access to EMRs. These included audit/feedback, pharmacist-led medication reconciliation, paper or electronic templates, and multi-pronged education interventions. To our knowledge, this is the first systematic review of the effectiveness of interventions to improve ED documentation.

Our findings mirror those of related studies on the effectiveness of interventions to improve written and verbal communication in hospital settings [3, 5, 57]. Prior research in non-ED settings indicates that active (e.g. audit/feedback or templates) and/or multifaceted interventions that explicitly engage participants may be more effective than passive interventions (e.g. printed education materials) in effecting lasting changes in physicians' documentation behavior [15, 58-61]. While the findings from our review tend to confirm that active interventions such as audit/feedback, reminders, or templates and/or multiple interventions may improve physician documentation, we did observe mixed results with respect to documentation comprehensiveness and accuracy when these interventions were introduced into ED settings [26, 44, 47, 48, 50, 51, 54, 55]. The quality of the studies identified in this review, and variability in settings, outcome measures, and intervention duration across studies may have contributed to this finding; when appropriately designed for the context or 
environment in which they will operate, these interventions may prove even more effective in supporting improvements in physician documentation.

While many emergency settings are currently using, or considering implementing, electronic medical documentation systems to track patient care, the accessibility, usability, and time required to use EMR systems can, particularly in high pressure environments such as EDs, present barriers to achieving improvements in both physician documentation and associated patient care [34]. Although EMRs and other technologies may facilitate improvements in the quality of ED physician documentation, it is ultimately how these technologies are designed, implemented, and used that will determine their effectiveness [62]. For example, while many EMRs systems incorporate electronic templates into their design, templates do not, as this review suggests, in and of themselves guarantee the comprehensiveness and accuracy of the documentation recorded therein. Similarly, the mere presence of an EMR system does not automatically improve the quality of ED patient data; indeed, EMRs can perpetuate, even exacerbate, existing deficits in physician documentation [34]. When inadequately designed, implemented, or used, they may be no better, and perhaps worse, than unformatted paper charts [22, 23, 34, 63-65]. Further, as many emergency physicians continue to rely on paper charts or hybrid systems to record, track, and communicate the progress of patient care, no one documentation-improvement strategy may be effective in all settings.

Successful approaches will likely be those that can adapt to different settings, be seamlessly integrated into existing workflows, and garner widespread acceptance from all relevant stakeholders [66]. While our review found that interventions such as structured templates can improve the quality of paper and presumably electronic documentation, the increasing adoption of EMRs in EDs and other healthcare settings continues to require and inspire the development of a multitude of innovative solutions to facilitate the timely creation of comprehensive and accurate patient records [67]. For example, medical scribes, or "nonlicensed health care team members that document patient history and physical examination contemporaneously with the encounter" have been incorporated into EDs and other settings to improve the speed and comprehensiveness of physician documentation [68]. While studies evaluating the impact of medical scribes have reported positive outcomes with respect to patient flow and patient-provider satisfaction outcomes, medical scribes may also promote the creation of comprehensive high-quality patient care records $[68,69]$. Traditional health information management specialists can also play a role in monitoring and promoting the quality of both paper and EMR records.
Opportunities also exist to incorporate advances in artificial intelligence and machine learning into chart documentation processes $[70,71]$. In the future, it may be possible to embed artificial intelligence technologies, including machine learning, into EMR systems to alert physicians to patient information or physician orders that are potentially inaccurate, imprecise, incomplete, or inappropriate [72-79]. In Alberta, Canada efforts are underway to implement an EMR that will allow health information management specialists to conduct automatic documentation checks prior to patient visits, during care, and post discharge [80]. These checks will facilitate the consolidation of medication lists and allergies, and identify and alert physicians in real time to missing and incomplete chart information, and/or contradictions between patient histories and orders for medications or investigations.

While our review found little evidence of the effectiveness of speech recognition software in ED settings, recent advances in software development, machine learning, and bedside data capture suggest that effective, reliable, and efficient approaches to improving the quality of electronic patient notes may soon become commonplace [81-83]. In a recent study, Payne and colleagues described the development of a mobile app to convert voice-recorded patient notes into EMR-compatible text [83]. Other studies have reported on the development of automated or "digital scribes" to record and convert speech to text [81, 82]. Researchers at Stanford University (United States) are designing "digital scribe" software that will incorporate artificial intelligence and voice recognition to enable physicians to create comprehensive, quality patient data that can be uploaded to EMR systems in real time [81]. Other researchers at the University of California at Berkley (United States) have also described the creation of a prototype "automated medical scribe" that relies on "speech-processing modules" to "convert a transcribed spontaneous conversation into a concise and fully formatted report" [82]. If successful, these and similar initiatives may facilitate the creation of quality of electronic patient data, while simultaneously reducing administrative and workflow burdens associated with EMR systems [84].

Although ongoing technological advances may radically improve the quality of physician documentation, it is important to note that transforming documentation practices also requires changing learned behavior, or habits. Habits are patterns of behavior that are "acquired through incremental strengthening [repetition] of the association between a situation (cue) and an action [85]." As habits are formed over sustained periods of time, interventions designed to alter behavioral norms should similarly be of long duration. In a recent study on habit formation, researchers determined that while some individuals can easily adopt new personal and professional habits, others require much longer periods of time to 
alter behavioral norms [85]. Behavioral theorists further suggest that personal and environmental factors, including individual motivation and organizational culture and norms, can profoundly impact behavior change [86, 87]. Thus, the extent to which improvements in ED documentation are valued above other competing personal or organizational objectives, such as organizational expectations with respect to patient turnover, may affect the uptake and impact of these interventions. To effect lasting and meaningful improvements in ED documentation, it may be necessary to directly involve all stakeholders, including physicians and residents, in selecting, contextualizing, implementing, and conducting ongoing evaluations of multifaceted approaches to improving documentation quality in EDs [57, 61].

This study has caveats and limitations. While we employed an extremely comprehensive search strategy, inconsistencies in the indexing of studies in electronic databases and our decision to restrict our search to English or French language publications, may have impacted on our ability to identify all relevant studies. Further, variability in study design and outcomes assessed across studies limited our ability to quantitatively compare the outcomes from individual studies, and assess the overall effectiveness of many of these approaches. Finally, the preponderance of pre-experimental studies $(n=18)$ included in this review suggests that the literature on ED physician documentation improvement is yet in its infancy, and that further research is required to determine how best to encourage documentation improvements in these settings.

\section{Conclusions}

As more hospitals and primary care centers implement EMRs, healthcare providers, researchers, and decision makers will increasingly rely on patient health records to facilitate patient care, research, and health system planning; the need for accurate and complete physician documentation will only increase. At the systems level, documentation quality should and can be an indicator of health system performance. Achieving improvements in physician documentation is a complex process, requiring the active support of various stakeholders, and the implementation of systems that can be adapted to the demands of existing workflows, and the availability of adequate ongoing training [88]. While this review suggest that audit/feedback, reminders, templates and/or multiple interventions are potentially promising approaches to improving physician documentation, further research is needed to confirm these findings, and explore other approaches, including machine-learning and other emerging technologies, to advance ongoing improvements in physician documentation in ED settings.

\section{Additional file}

Additional file 1: MEDLINE Search Strategy. Copy of the search strategy used to identify relevant studies in the MEDLINE (OVID) database. (DOC $25 \mathrm{~kb}$ )

\section{Abbreviations}

CSN: Cross sectional study with control; ED: Emergency Department; EMR: Electronic medical record; PFUP: Prospective follow-up with comparison; PPC: Pre-post comparison; PPN: Pre-post no comparison; PRISMA: Preferred Reporting Items for Systematic Reviews and Meta-Analyses (PRISMA); RCT: Randomized controlled trial; RFUP: Retrospective follow-up with comparison; TSS: Time series study

\section{Acknowledgements}

Not applicable.

Consent to publication

Not Applicable.

\section{Funding}

This review was supported by the Canadian Institutes of Health Research [grant number 111753].

\section{Availability of data and materials}

All data generated or analysed during this study are included in this published article.

\section{Authors' contributions}

$\mathrm{HQ}$ and $C A B$ conceived of the study, DLL developed and ran the search strategies; DLL, HQ, CC, DH, and CAB screened abstracts and full-text studies; $\mathrm{DLL}$ and $\mathrm{KL}$ conducted a quality assessment of included studies; $\mathrm{DLL}, \mathrm{HQ}, \mathrm{KL}$ $J$ J, and $C A B$ extracted data from included studies, and all authors contributed to and approved the final manuscript.

Ethics approval and consent to participate Not Applicable.

Competing interests

The authors declare that they have no competing interests.

\section{Publisher's Note}

Springer Nature remains neutral with regard to jurisdictional claims in published maps and institutional affiliations.

\section{Author details}

${ }^{1}$ Department of Community Health Sciences, Cumming School of Medicine, University of Calgary, 3330 Hospital Drive NW, Calgary, AB T2N4N1, Canada.

${ }^{2}$ Department of Psychiatry, Cumming School of Medicine, University of

Calgary, 3330 Hospital Drive NW, Calgary, AB T2N4N1, Canada.

Received: 2 May 2018 Accepted: 12 October 2018

Published online: 25 October 2018

References

1. Physician Documentation Expert Panel. A guide to better physician documentation. Toronto: Ontario Ministry of Health and Long-Term Care; 2006

2. Foster S, Manser T. The effects of patient handoff characteristics on subsequent care: a systematic review and areas for future research. Acad Med. 2012;87(8):1105-24.

3. Kripalani S, LeFevre F, Phillips CO, Williams MV, Basaviah P, Baker DW. Deficits in communication and information transfer between hospital-based and primary care physicians: implications for patient safety and continuity of care. JAMA. 2007:297(8):831-41.

4. Keers RN, Williams SD, Cooke J, Ashcroft DM. Causes of medication administration errors in hospitals: a systematic review of quantitative and qualitative evidence. Drug Saf. 2013;36(11):1045-67. 
5. Motamedi SM, Posadas-Calleja J, Straus S, Bates DW, Lorenzetti DL, Baylis B, et al. The efficacy of computer-enabled discharge communication interventions: a systematic review. BMJ Qual Saf. 2011;20(5):403-15.

6. Ross S, Ryan C, Duncan EM, Francis JJ, Johnston M, Ker JS, et al. Perceived causes of prescribing errors by junior doctors in hospital inpatients: a study from the PROTECT programme. BMJ Qual Saf. 2013;22(2):97-102.

7. So L, Beck CA, Brien S, Kennedy J, Feasby TE, Ghali WA, et al. Chart documentation quality and its relationship to the validity of administrative data discharge records. Health Informatics J. 2010;16(2):101-13.

8. Watkins T, Aguero S, Jaecks M. Impact of clinical decision support on time to order resolution for patients with documented allergies. Pharmacy (Basel). 2018;6(3):80. Available from: https://www.mdpi.com/2226-4787/6/3/80

9. Davidson SJ, Zwemer FL Jr, Nathanson LA, Sable KN, Khan AN. Where's the beef? The promise and the reality of clinical documentation. Acad Emerg Med. 2004;11(11):1127-34

10. Quan H, Parsons GA, Ghali WA. Assessing accuracy of diagnosis-type indicators for flagging complications in administrative data. J Clin Epidemiol. 2004;57(4):366-72.

11. Juurlink D, Preyra C, Croxford R, Chong A, Austin P, Tu J, et al. Canadian Institute for Health Information Discharge Abstract Database: a validation study. Institute for Clinical Evaluative Sciences: Toronto; 2006.

12. Silfen E. Documentation and coding of ED patient encounters: an evaluation of the accuracy of an electronic medical record. Am J Emerg Med. 2006;24(6):664-78.

13. Dawdy MR, Munter DW, Gilmore RA. Correlation of patient entry rates and physician documentation errors in dictated and handwritten emergency treatment records. Am J Emerg Med. 1997;15(2):115-7.

14. Stiell A, Forster AJ, Stiell IG, van WC. Prevalence of information gaps in the emergency department and the effect on patient outcomes. CMAJ. 2003; 169(10):1023-8

15. Cheung DS, Kelly JJ, Beach C, Berkeley RP, Bitterman RA, Broida Rl, et al. Improving handoffs in the emergency department. Ann Emerg Med. 2010;55(2):171-80.

16. di Martino P, Leoli F, Cinotti F, Virga A, Gatta L, Kleefield S, et al. Improving vital sign documentation at triage: an emergency department quality improvement project. J Patient Saf. 2011;7(1):26-9.

17. Yu KT, Green RA. Critical aspects of emergency department documentation and communication. Emerg Med Clin North Am. 2009;27(4):641-54 ix.

18. Burke HB, Sessums LL, Hoang A, Becher DA, Fontelo P, Liu F, et al. Electronic health records improve clinical note quality. J Am Med Inform Assoc. 2015;22(1):199-205.

19. D'Huyvetter C, Lang AM, Heimer DM, Cogbill TH. Efficiencies gained by using electronic medical record and reports in trauma documentation. J Trauma Nurs. 2014;21(2):68-71.

20. Neri PM, Redden L, Poole S, Pozner CN, Horsky J, Raja AS, et al. Emergency medicine resident physicians' perceptions of electronic documentation and workflow: a mixed methods study. Appl Clin Inform. 2015;6(1):27-41.

21. Nguyen L, Bellucci E, Nguyen LT. Electronic health records implementation: an evaluation of information system impact and contingency factors. Int J Med Inform. 2014;83(11):779-96.

22. Park SY, Lee SY, Chen Y. The effects of EMR deployment on doctors' work practices: a qualitative study in the emergency department of a teaching hospital. Int J Med Inform. 2012;81(3):204-17.

23. Weis JM, Levy PC. Copy, paste, and cloned notes in electronic health records: prevalence, benefits, risks, and best practice recommendations. Chest. 2014;145(3):632-8.

24. Campanella P, Lovato E, Marone C, Fallacara L, Mancuso A, Ricciardi W, et al. The impact of electronic health records on healthcare quality: a systematic review and meta-analysis. Eur J Pub Health. 2016;26(1):60-4.

25. Mamlin BW, Tierney WM. The promise of information and communication technology in healthcare: extracting value from the chaos. Am J Med Sci. 2016;351(1):59-68

26. Alkasab TK, Alkasab JR, Abujudeh HH. Effects of a computerized provider order entry system on clinical histories provided in emergency department radiology requisitions. J Am Coll Radiol. 2009;6(3):194-200.

27. Bizovi KE, Beckley BE, McDade MC, Adams AL, Lowe RA, Zechnich AD, et al. The effect of computer-assisted prescription writing on emergency department prescription errors. Acad Emerg Med. 2002;9(11):1168.

28. Buller-Close $K$, Schriger DL, Baraff $\sqcup$. Heterogeneous effect of an emergency department expert charting system. Ann Emerg Med. 2003;41(5):644-52.

29. Day F, Hoang LP, Ouk S, Nagda S, Schriger DL. The impact of a guidelinedriven computer charting system on the emergency care of patients with acute low back pain. In Gardner RM editor. Proc Annu Symp Comput Appl Med Care; 1995 Oct 28-Nov 1; New Orleans. Bethesda: American Medical Informatics Association; 1995. p. 576-80.
30. Perry JJ, Sutherland J, Symington C, Dorland K, Mansour M, Stiell IG. Assessment of the impact on time to complete medical record using an electronic medical record versus a paper record on emergency department patients: a study. Emerg Med J. 2014;31(12):980-5.

31. Schriger DL, Baraff LJ, Buller K, Shendrikar MA, Nagda S, Lin EJ, et al. Implementation of clinical guidelines via a computer charting system: effect on the care of febrile children less than three years of age. J Am Med Inform Assoc. 2000;7(2):186-95.

32. Linder JA, Schnipper JL, Middleton B. Method of electronic health record documentation and quality of primary care. J Am Med Inform Assoc. 2012; 19(6):1019-24.

33. Hayrinen $K$, Saranto K, Nykanen P. Definition, structure, content, use and impacts of electronic health records: a review of the research literature. Int J Med Inform. 2008;77(5):291-304.

34. Lo MD, Rutman LE, Migita RT, Woodward GA. Rapid electronic provider documentation design and implementation in an academic pediatric emergency department. Pediatr Emerg Care. 2015;31(11):798-804.

35. Moher D, Liberati A, Tetzlaff J, Altman DG. Preferred reporting items for systematic reviews and meta-analyses: the PRISMA statement. PLoS Med. 2009;6(7):e1000097.

36. Downs SH, Black N. The feasibility of creating a checklist for the assessment of the methodological quality both of randomised and non-randomised studies of health care interventions. J Epidemiol Community Health. 1998; 52(6):377-84.

37. Hanson JM, Johnson G, Clancy MJ. The effect of audit and feedback on data recording in the accident and emergency department. J Accid Emerg Med. 1994;11(1):45-7.

38. Heidt JW, Griffey R. Physician documentation of critical care time while working in the emergency department. Acad Emerg Med. 2012;19:S115-6.

39. Cole AB, Counselman FL. Comparison of transcribed and handwritten emergency department charts in the evaluation of chest pain. Ann Emerg Med. 1995;25(4):445-50

40. Zick RG, Olsen J. Voice recognition software versus a traditional transcription service for physician charting in the ED. Am J Emerg Med. 2001;19(4):295-8.

41. Otillio JK, Park DB, Hewett KM, Losek JD. Effectiveness of a medicolegal lecture on risk-reduction medical record documentation by pediatric residents. Clin Pediatr. 2014;53(5):479-85.

42. Vasileff HM, Whitten LE, Pink JA, Goldsworthy SJ, Angley MT. The effect on medication errors of pharmacists charting medication in an emergency department. Pharm World Sci. 2009;31(3):373-9.

43. De Winter S, Vanbrabant P, Spriet I, Desruelles D, Indevuyst C, Knockaert D, et al. A simple tool to improve medication reconciliation at the emergency department. Eur J Intern Med. 2011;22(4):382-5.

44. Van Amstel LL, Lafleur DL, Blake K. Raising our HEADSS: adolescent psychosocial documentation in the emergency department. Acad Emerg Med. 2004;11(6):648-55.

45. Goodyear HM, Lloyd BW. Can admission notes be improved by using preprinted assessment sheets? Qual Health Care. 1995;4(3):190-3.

46. Humphreys T. Preformatted charts improve documentation in the emergency department. Ann Emerg Med. 1992;21(5):534-40.

47. Kondziolka D, Schwartz ML, Walters BC, McNeill I. The Sunnybrook Neurotrauma assessment record - improving trauma data-collection. J Trauma. 1989;29(6):730-5.

48. O'Connor AE, Finnel L, Reid J. Do preformatted charts improve doctors' documentation in a rural hospital emergency department? A prospective trial. N Z Med J. 2001;114(1141):443-4.

49. Schnieden V, Good S. Use of a psychiatric proforma for accident and emergency officers. J Accid Emerg Med. 1996;13(3):180-3.

50. Wrenn K, Rodewald L, Lumb E, Slovis C. The use of structured, complaintspecific patient encounter forms in the emergency department. Ann Emerg Med. 1993:22(5):805-12.

51. Marill KA, Gauharou ES, Nelson BK, Peterson MA, Curtis RL, Gonzalez MR. Prospective, randomized trial of template-assisted versus undirected written recording of physician records in the emergency department. Ann Emerg Med. 1999;33(5):500-9.

52. Carter KA, Dawson BC, Brewer K, Lawson L. RVU ready? Preparing emergency medicine resident physicians in documentation for an incentive-based work environment. Acad Emerg Med. 2009;16(5):423-8.

53. Dexter SC, Hayashi D, Tysome JR. The ANKLe score: an audit of otolaryngology emergency clinic record keeping. Ann R Coll Surg Engl. 2008;90(3):231-4. 
54. Teo S, Hanson R, Van AP, Giles H, Fasher B, Davis AM, et al. Improving asthma documentation in a paediatric emergency department. J Paediatr Child Health. 1995;31(2):130-3.

55. Voaklander DC, Cummings GE, Borden K, Policicchio C, Vincenten J. Pilot intervention to improve the documentation of pediatric injuries in the emergency department, critical care medicine as a subspecialty of emergency medicine. CJEM. 2000;2(4):252-7.

56. Kuhn T, Basch P, Barr M, Yackel T. Clinical documentation in the 21st century: executive summary of a policy position paper from the American College of Physicians. Ann Intern Med. 2015;162(4):301-3.

57. Boonstra A, Versluis A, Vos JF. Implementing electronic health records in hospitals: a systematic literature review. BMC Health Serv Res. 2014;14:370

58. Grudniewicz A, Kealy R, Rodseth RN, Hamid J, Rudoler D, Straus SE. What is the effectiveness of printed educational materials on primary care physician knowledge, behaviour, and patient outcomes: a systematic review and meta-analyses. Implement Sci. 2015;10:164

59. Ivers N, Jamtvedt G, Flottorp S, Young JM, Odgaard-Jensen J, French SD, et al. Audit and feedback: effects on professional practice and healthcare outcomes. Cochrane Database Syst Rev. 2012;6:CD000259.

60. Mostofian F, Ruban C, Simunovic N, Bhandari M. Changing physician behavior: what works? Am J Manag Care. 2015;21(1):75-84.

61. Squires JE, Sullivan K, Eccles MP, Worswick J, Grimshaw JM. Are multifaceted interventions more effective than single-component interventions in changing health-care professionals' behaviours? An overview of systematic reviews. Implement Sci. 2014;9:152.

62. Wang N, Yu P, Hailey D. Description and comparison of quality of electronic versus paper-based resident admission forms in Australian aged care facilities. Int J Med Inform. 2013:82(5):313-24.

63. Bowman S. Impact of electronic health record systems on information integrity: quality and safety implications. Perspect Health Inf Manag. 2013;10:1c.

64. Carayon P, Wetterneck TB, Alyousef B, Brown RL, Cartmill RS, McGuire K, et al. Impact of electronic health record technology on the work and workflow of physicians in the intensive care unit. Int J Med Inform. 2015;84(8):578-94.

65. Wormer BA, Colavita PD, Yokeley WT, Bradley JF III, Williams KB, Walters AL, et al. Impact of implementing an electronic health record on surgical resident work flow, duty hours, and operative experience. Am Surg. 2015: 81(2):172-7.

66. Callen J, Paoloni R, Li J, Stewart M, Gibson K, Georgiou A, et al. Perceptions of the effect of information and communication technology on the quality of care delivered in emergency departments: a cross-site qualitative study. Ann Emerg Med. 2013;61(2):131-44

67. Kaufman DR, Sheehan B, Stetson P, Bhatt AR, Field Al, Patel C, et al. Natural language processing-enabled and conventional data capture methods for input to electronic health records: a comparative usability study. JMIR Med Inform. 2016;4(4):e35.

68. Heaton HA, Castaneda-Guarderas A, Trotter ER, Erwin PJ, Bellolio MF. Effect of scribes on patient throughput, revenue, and patient and provider satisfaction: a systematic review and meta-analysis. Am J Emerg Med. 2016; 34(10):2018-28.

69. Odenheimer S, Goyal D, Jones VG, Rosenblum R, Ho L, Chan AS. Patient acceptance of remote scribing powered by Google glass in outpatient dermatology: cross-sectional study. J Med Internet Res. 2018;20(6):e10762.

70. Berlyand Y, Raja AS, Dorner SC, Prabhakar AM, Sonis JD, Gottumukkala RV, et al. How artificial intelligence could transform emergency department operations. Am J Emerg Med. 2018;36(8):1515-7.

71. Lin SY, Shanafelt TD, Asch SM. Reimagining clinical documentation with artificial intelligence. Mayo Clin Proc. 2018;93(5):563-5.

72. Forsyth AW, Barzilay R, Hughes KS, Lui D, Lorenz KA, Enzinger A, et al. Machine learning methods to extract documentation of breast cancer symptoms from electronic health records. J Pain Symptom Manag. 2018; 55(6):1492-9.

73. Gobbel GT, Reeves R, Jayaramaraja S, Giuse D, Speroff T, Brown SH, et al Development and evaluation of RapTAT: a machine learning system for concept mapping of phrases from medical narratives. J Biomed Inform. 2014;48:54-65

74. Li Q, Spooner SA, Kaiser M, Lingren N, Robbins J, Lingren T, et al. An end-toend hybrid algorithm for automated medication discrepancy detection. BMC Med Inform Decis Mak. 2015:15:37.

75. McCoy A, Das R. Reducing patient mortality, length of stay and readmissions through machine learning-based sepsis prediction in the emergency department, intensive care unit and hospital floor units. BMJ Open Qual. 2017:6(2):e000158.

76. Mehta N, Devarakonda MV. Machine learning, natural language programming, and electronic health records: the next step in the artificial intelligence journey? J Allergy Clin Immunol. 2018;141(6):2019-21.

77. Schiff GD, Volk LA, Volodarskaya M, Williams DH, Walsh L, Myers SG, et al. Screening for medication errors using an outlier detection system. J Am Med Inform Assoc. 2017;24(2):281-7.

78. Tou H, Yao L, Wei Z, Zhuang X, Zhang B. Automatic infection detection based on electronic medical records. BMC Bioinformatics. 2018;19(Suppl 5):117.

79. Wang Z, Shah AD, Tate AR, Denaxas S, Shawe-Taylor J, Hemingway H. Extracting diagnoses and investigation results from unstructured text in electronic health records by semi-supervised machine learning. PLoS One. 2012;7(1):e30412.

80. Davis Z, Khansa L. Evaluating the epic electronic medical record system: a dichotomy in perspectives and solution recommendations. Health Policy Technol. 2016;5(1):65-73.

81. Collier R. Rethinking EHR interfaces to reduce click fatigue and physician burnout. CMAJ. 2018;190(33):E994-5.

82. Finley G, Edwards E, Robinson A, Brenndoerfer M, Sadoughi N, Fone J, et al. An automated medical scribe for documenting clinical encounters. Proceedings of the 2018 Conference of the north American chapter of the Association for Computational Linguistics: demonstrations New Orleans June1-6 2018. Stroudsberg, Association for Computational Linguistics:11-15.

83. Payne TH, Alonso WD, Markiel JA, Lybarger K, White AA. Using voice to create hospital progress notes: description of a mobile application and supporting system integrated with a commercial electronic health record. J Biomed Inform. 2018;77:91-6.

84. Kruse CS, Kristof C, Jones B, Mitchell E, Martinez A. Barriers to electronic health record adoption: a systematic literature review. J Med Syst. 2016; 40(12):252.

85. Lally $\mathrm{P}$, van Jaarsveld CHM, Potts HWW, Wardle J. How are habits formed: modelling habit formation in the real world. Eur J Soc Psychol. 2010;40(6): 998-1009.

86. Bandura A. Self-efficacy: toward a unifying theory of behavioral change. Psychol Rev. 1977;84(2):191-215.

87. Skinner BF. Science and human behavior. New York: Free Press; 1953.

88. McGinn CA, Grenier S, Duplantie J, Shaw N, Sicotte C, Mathieu L, et al. Comparison of user groups' perspectives of barriers and facilitators to implementing electronic health records: a systematic review. BMC Med. 2011;9:46
Ready to submit your research? Choose BMC and benefit from:

- fast, convenient online submission

- thorough peer review by experienced researchers in your field

- rapid publication on acceptance

- support for research data, including large and complex data types

- gold Open Access which fosters wider collaboration and increased citations

- maximum visibility for your research: over $100 \mathrm{M}$ website views per year

At BMC, research is always in progress.

Learn more biomedcentral.com/submissions 